\title{
Value of CNRIP1 promoter methylation in colorectal cancer screening and prognosis assessment and its influence on the activity of cancer cells
}

Ting Zhang ${ }^{1}$, Ge Cui ${ }^{2}$, Yun-Liang Yao ${ }^{3}$, Qi-Chun Wang ${ }^{1}$, Hong-Guang Gu ${ }^{1}$, Xi-Ning Li ${ }^{1}$, Hui Zhang ${ }^{3}$, Wen-Ming Feng', Qi-Lin Shi², Weiwei Cui ${ }^{5}$

\begin{abstract}
${ }^{1}$ Department of Pathology, School of Medicine, Huzhou University, Huzhou, China ${ }^{2}$ Department of Pathology, First Affiliated Hospital of Huzhou University, Huzhou, China ${ }^{3}$ Department of Microbiology and Immunology, School of Medicine, Huzhou University, Huzhou, China

${ }^{4}$ Department of Surgery, First Affiliated Hospital of Huzhou University, Huzhou, China ${ }^{5}$ Department of Pharmacy, Zichuan District Hospital, Zibo, Shangdong, China
\end{abstract}

Submitted: 26 July 2016

Accepted: 21 September 2016

Arch Med Sci 2017; 13, 6: 1281-1294

DOI: https://doi.org/10.5114/aoms.2017.65829

Copyright (c) 2017 Termedia \& Banach

\section{Abstract}

Introduction: The aim of the study was to investigate the effect of CNRIP1 promoter methylation on the proliferative, invasive and migration potential of colorectal cancer cells, including its potential use for the early detection and prognostic assessment of colorectal cancer.

Material and methods: Quantitative methylation-specific PCR (qMSP) was used to detect the methylation status of the CNRIP1 promoter region in peripheral blood samples drawn from patients with colorectal adenocarcinoma, benign colorectal adenoma, and matched healthy controls. Putative CPG methylation sites were then pyrosequenced. We subsequently suppressed CNRIP1 methylation within colon cancer cells via treatment with 5 -azacytidine and overexpressed colon cancer cells by transfection with a CNRIP1-overexpression pCDNA3.0 plasmid. Thereafter, the CNRIP1 methylation status and mRNA and protein expressions levels were determined. Finally, the proliferative, invasive and migration abilities of cell lines were determined with the CCK-8 and Transwell cell assays.

Results: There were differences in the methylation status at loci 2216, 2226, 2231,2245 , and 2254 within the promoter region of CNRIP1 between patients with colorectal adenocarcinoma, colorectal adenoma, and healthy volunteers. The methylation status of $\mathrm{CpG}$ sequence 2245 significantly correlated with tumor diameter, invasion depth, TNM stage, grade, and lymph node metastasis $(p<0.05)$. The proliferative, invasive and migration abilities of colon cancer cells treated with 5-azaC or transfected with a CNRIP1-overexpression plasmid were significantly impaired relative to negative controls $(p<0.05)$.

Conclusions: The methylation status at locus 2245 within the CNRIP1 promoter region has potential value for the early detection and prognostic evaluation of colorectal cancers. Demethylation of the CNRIP1 promoter or overexpression of CNRIP1 can reduce the proliferative and migration abilities of colon cancer cells.

Key words: colorectal adenocarcinoma, cannabinoid receptor interacting protein 1 (CNRIP1), early detection, methylation, prognostic evaluation, screening, tumor cell activity.

\author{
Corresponding author: \\ Ge Cui \\ Department of Pathology \\ First Affiliated Hospital \\ of Huzhou University \\ 158 Guangchanghou Road \\ 313000 Huzhou, China \\ Phone: +8613511234403 \\ E-mail: witcui@foxmail.com
}




\section{Introduction}

Colorectal cancer (CRC) is a formidable burden worldwide. Globally, there are 100 million new CRC cases per annum, with $\sim 21 \%$ of those proving fatal [1]. Whilst outcomes are generally favorable if detected and treated early, when $74 \%$ of patients can expect to live 5 years, $25 \%$ of all CRCs are only detected when the tumor has metastasized, when only $6 \%$ of patients survive 5 years. Approximately $50 \%$ of patients die from early or postoperative metastasis or cancer recurrence [2-4].

An estimated $93 \%$ of CRCs evolve from a premalignant adenoma via the so-called adenomacarcinoma sequence [3]. This transitory period is lengthy (5-7 years [2]), which provides a window of opportunity where dysplastic lesions can be detected and excised at the precancerous phase, which is generally curative, or at an early, localized cancerous stage, which is highly treatable and associated with favorable outcomes. The discovery of molecular markers specific to precancerous colorectal adenomas and early, localized colorectal cancers would surely aid their early detection and prognosis assessment.

Hypermethylation of DNA sequences within promoter regions of crucial genes is an early event of tumor development, occurring even before cancer gene mutations [5, 6]. DNA methylation is a method of gene silencing in both prokaryotes and eukaryotes, whereby the enzyme DNA methyltransferase adds a methyl group at the fifth carbon of cytosines immediately followed by a guanine. Blood samples are favored for surgical or endoscopic biopsies as screening specimens, and aberrant DNA methylation profiles are more stable in blood samples compared to circulating mRNA [7-10]. Accordingly, aberrant DNA methylation patterns may serve as a screening tool for CRC [7, 11-14].

Hypermethylation of the promoter region of cannabinoid receptor interacting protein 1 (CNRIP1) has been observed in colorectal adenocarcinoma tissue [15]. Current evidence suggests that CNRIP1 regulates the eye and neural development of Xenopus laevis [16]. Furthermore, aberrant DNA methylation biomarkers have been used to detect cholangiocarcinoma in biliary brush samples [17] and diffuse-type early gastric carcinogenesis [18]. However, the correlation between the methylation status of the CNRIP1 promoter region within peripheral blood of patients with colorectal adenocarcinoma and its association with clinicopathological characteristics has not yet been reported. Accordingly, the present study sought to evaluate the use of CNRIP1 methylation for the early detection and prognostic assessment of colorectal cancers. We used quantitative methylation-specific polymerase chain reaction (PCR) (qMSP) technology [19] to detect the methylation levels of the CpG island in the CNRIP1 promoter region in peripheral blood drawn from patients diagnosed with colorectal adenocarcinoma and colorectal adenoma and within the peripheral blood samples drawn from healthy volunteers. Furthermore, the proliferative, invasive and migration potential of colon cancer cells induced to have either suppressed methylation or CNRIP1 overexpression were determined in parallel to that of unaltered colon cancer and normal colon cell lines.

\section{Material and methods}

\section{Ethical review}

The present study was ethically approved by the Clinical Ethics Committee and Research Ethics Committees at the First Affiliated Hospital of Huzhou University, China.

\section{Blood samples}

Blood samples were collected from 100 CRC patients enrolled in our hospital from March 2013 to January 2014 (28 males, 22 females; 48-82 years old, 69.35 on average), 20 colorectal adenoma patients (10 males, 10 females; 38-61 years old, 52.61 on average), and 20 healthy volunteers (10 males, 10 females; 37-75 years old, 49.23 on average). Patients with colorectal adenocarcinoma or adenoma were admitted to hospital for the first time and had no cancer treatment before the blood draw. Patients with the following diagnoses were excluded: familial adenomatous polyposis (FAP), hereditary nonpolyposis colorectal cancer (HNPPC), anal canal cancer, acute or chronic inflammation, serious cardiovascular or cerebrovascular disease (such as acute coronary syndrome, chronic cardiac dysfunction, cerebral vascular accident), liver and kidney dysfunction, or other stress conditions. Healthy controls had no previous diagnoses of any major disease at health check-up and no history of cancer in the immediate relatives within three generations. Patients fasted overnight before the blood draw, upon which $5 \mathrm{ml}$ of peripheral venous blood was collected in the early morning using an EDTA- $\mathrm{K}^{2}$ anticoagulation vacuum blood collection tube.

\section{Baseline characteristics}

Baseline characteristics (sex and age) were obtained from adenocarcinoma and adenoma patients and healthy volunteers. Clinicopathological data (tumor location, type, diameter, histological grade, primary tumor invasion depth, vascular/ perineural invasion, lymph node metastasis, and remote metastasis) were ascertained by an experienced pathologist. CRC patients were classified according to the TNM system based on the Amer- 
ican Joint Committee on Cancer (AJCC) and Union for International Cancer Control (UICC) 2009 staging system for colorectal cancer ( $7^{\text {th }}$ edition) [20].

\section{CNRIP1 promoter methylation status in peripheral blood}

Bisulfite modification was performed with an EpiTect bisulfite kit (QIAGEN, cat. no. 59104) completed as per the manufacturer's instructions. Briefly, DNA was dissolved in $3.6 \mathrm{~mol} / \mathrm{l}$ sulfite solution, to which $800 \mu$ l of RNase-free water was added and mixed thoroughly, added into a $200 \mu \mathrm{l}$ PCR tube, mixed at room temperature, and set aside. A Stratagene Mx3005P Real-Time PCR Detector (Agilent Technologies, Santa Clara, CA, USA) was used for DNA sulfite transformation, in a reaction totaling $5 \mathrm{~h}$. The reactions were then incubated overnight at $20^{\circ} \mathrm{C}$ within the thermocycler.

The pyrosequencing: primers were designed using PyroMark Assay Design 2.0 (Qiagen, Germany). These primers were: CNRIP1 F1: 5'-GGTTATTTTTTTTTAAGTTTTGGAAAGATT-3'; CNRIP1 R1: 5'-ATTTACCCACCACAATCCCCTTCA-3'; CNRIP1 S1: 5'-GGATTAGAGAGTAGTAGTGTTTA-3' (5'-end modified by Biotin). Primers were synthesized by the Shenzhen BGI Company. The PCR was undertaken using an ABI PCR System 9700 (Applied Biosystems). The pyrosequencing reaction was undertaken using a PyroMark Q96 ID Pyrosequencing detector (QIAGEN). The methylation status of each locus was analyzed automatically by the Pyro Q-CpG software.

\section{Cell cultures}

SW620 (ATCC CCL227) and LoVo (ATCC CCL229) human colon cancer cell lines and the FHC normal human (ATCC CRL-1831) colon cell line were cultured in Dulbecco's Modified Eagle's Medium (Life Technologies, cat. no. 11965, Lot. 1177305) with $10 \%$ fetal bovine serum (Gibco, 10099-141FBS) supplemented with $100 \mathrm{U} / \mathrm{ml}$ penicillin and $0.1 \mathrm{mg} / \mathrm{ml}$ streptomycin at $37^{\circ} \mathrm{C}$ in a saturated humid atmosphere containing $5 \% \mathrm{CO}_{2}$. Cells were supplemented with $0.6 \mu \mathrm{g} / \mathrm{ml}$ trypsin (cat. no. T1426, Sigma, St. Louis, USA). Colon cancer cells were divided into four groups: 1) transfected with CNRIP1-shRNA (CNRIP1+ group; see CNRIP1 overexpression); 2) transfected with an empty vector (EV group); 3) treated with 5-azacytidine (5-azaC-treated group; see CNRIP1 methylation suppression); and 4) untreated and cultured in normal medium (control group).

\section{CNRIP1 overexpression}

CNRIP1+ and EV cells were transfected with either a CNRIP1-pCDNA3.0 plasmid or pCDNA3.0 plasmid, respectively. All transfections were per- formed using Lipofectamine 2000 reagent (cat. no. 52887; Invitrogen) used in accordance with the manufacturer's instructions. The primer was synthesized using a CNRIP1 CDS and the pCDNA3.0 (Invitrogen) vector sequence as a foundation. The length of the amplified fragment was $522 \mathrm{bp}$. The sequences of the CNRIP1-NotI F and CNRIP1-HindIII R primers were $5^{\prime}$-ATAAGAATGCGGCCGCAGACCCTCGCCCAGACATG-3' and 5'-CCCAAGCTTAGTAGCATCAGAAAGAGCCAC-3', respectively.

\section{Suppression of CNRIP1 methylation}

Colon cancer cells $\left(1.0 \times 10^{5} /\right.$ well) were cultured in a 6 -well plate containing DMEM with $10 \%$ FBS. The medium was replaced every $24 \mathrm{~h}$ with fresh medium containing $5 \mu \mathrm{M}$ 5-azaC (EpiTect Bisulfite Kit, cat. no. 59104, QIAGEN, Hilden, Germany) for $72 \mathrm{~h}$ in total.

\section{Levels of CNRIP1 promoter methylation in colon cells}

Genomic DNA was extracted and quantitated with a Biospin genomic DNA extraction kit (cat. no. BSC05S1). The EpiTect Bisulfite Kit (QIAGEN; cat. no. 59104) was used for bisulfite modification. The PCR primers (CNRIP1-F (5'-GAGTAGTAGTGTTTATTTTA-3') and CNRIP1-R (5'-ACAATTTAAACTCCTCCTAAAAC-3')) were synthesized by Shanghai Sangon Biotechnology. The PCR-amplified fragment length was 476 bp. TaKaRa Taq (Hot Start Version) was used for PCR amplification of the target gene. The PCR product was recovered with a Gel Extraction Kit (OMEGA) and was ligated into a cloning T-vector. The successfully cloned PCR product was selected and entrusted to Shanghai Sangon Biotechnology for sequencing. From the sequence data, the sequence similarity to the target sequences (\%), C-T conversion efficiency (\%), methylation statuses of each CG pair (dot plot), and methylation rate of each CG pair (\%) were calculated.

\section{Expression of CNRIP1 mRNA in colon cancer cells}

The mRNA expression of CNRIP1 within SW620, LoVo, and FHC cell lines was determined with a Mx3005P Real-Time PCR Detector. $\beta$-actin was used as the housekeeping gene for qPCR. The primers were as follows: CNRIP1S (5'-GCATCCAGCCTAATGACGG-3'), CNRIP1AS (5'-TCAGTTCCAGTGGGACAAGC-3'), GAPDH forward (5'-TGTTCGTCATGGGTGTGAA-3'), and GAPDH reverse (5'-ATGGCATGGACTGTGGTCAT-3'). Polymerase chain reaction (PCR) primers were designed and synthesized using Primer Premier 6.0 software (Premier Biosoft International, Palo Alto, USA). SW620 and LoVo colon cancer cells were seeded into 6-well 
plates ( $10^{5}$ cells/well) and incubated for $24 \mathrm{~h}$. RNA was extracted from cell lines using TRIzol reagent (Cat. 15596-018, Invitrogen, Darmstadt, Germany). SYBR Green fluorescence was measured at $72^{\circ} \mathrm{C}$ during the extension stage. The data were analyzed using the delta-delta cycle threshold (Ct) method [21]. All experiments were repeated in triplicate.

\section{Expression of CNRIP1 protein in colon cancer cells}

Western blotting was used to detect levels of CNRIP1 protein. Colon cancer cells were seeded into 6-well plates $\left(10^{6}\right.$ cells/well) and incubated for $24 \mathrm{~h}$. After cell lysis with RIPA buffer, the concentration of total protein was determined by BCA (Pierce TM BCA protein assay kit). $50 \mu \mathrm{g}$ of cell lysates were electrophoresed at $100-120 \mathrm{~V}$ for $1.5 \mathrm{~h}$, transferred to a polyvinylidene fluoride membrane, blocked with 5\% non-fat milk, and incubated with 1 part anti-CNRIP1 antibody (Abcam, ab167087) and 2,000 parts PBS for $8 \mathrm{~h}$ at $25^{\circ} \mathrm{C}$. Later, the Western blot was incubated with 1 part goat anti-rabbit IgG-HRP conjugate (BOSTER, cat. no. BA1054) and 20,000 parts PBS for $40 \mathrm{~min}$ at $25^{\circ} \mathrm{C}$. The optical densities of protein bands were visualized with Image-Pro Plus 6.0 software using 1 part anti- $\beta$-actin antibody (Abcam, ab8245) and 400 parts PBS as an internal reference. Expression of proteins was determined in triplicate. The relative protein expression was calculated by dividing the gray value of the target protein with the gray value of the internal reference protein.

\section{Proliferation ability of colon cancer cell lines}

The proliferative ability of colon cancer cells was determined with a CCK-8 assay (YEASEN Cell Counting Kit-8, QF0025). Briefly, $5 \times 10^{4}$ colon cancer cells were seeded per microwell of a 96well cell culture plate (Corning, 07-200-87). After incubating for $0,6,12$, and $24 \mathrm{~h}, 10 \mu \mathrm{l}$ of CCK-8 solution was added and incubated for $2 \mathrm{~h}$. Following this, the $\mathrm{OD}_{450}$ was measured in triplicate using a microplate reader. A cell growth curve was plotted to calculate the proliferative ability of cells, which equaled the mean $\mathrm{OD}_{450}$ of experiment cells - mean $\mathrm{OD}_{450}$ of control cells.

\section{Migration and invasion ability of colon cancer cell lines}

The migration and invasive ability of colon cancer cells were determined by a Transwell assay consisting of a 24-well Transwell culture insert with polycarbonate membrane and $8.0 \mu \mathrm{m}$ pores (BD FALCON, Franklin Lakes, USA). Briefly, the upper surface of the polycarbonate membrane of the Transwell insert was coated with 1 part Matrigel $(50 \mathrm{mg} / \mathrm{l})$ and 8 parts serum-free medium and was then allowed to air dry at $4^{\circ} \mathrm{C}$. Colon cancer cells were trypsinized, centrifuged at $12,000 \mathrm{~g}$ for $10 \mathrm{~min}$, and the supernatant discarded. The cells were then resuspended in serum-free medium, counted, and diluted to a density of $5 \times 10^{5} / \mathrm{ml}$. A total of $500 \mu$ l of DMEM (Life Technologies, cat. no. 11965 , lot no. 1177305$)$ was added to each well. Next, 100-200 $\mu \mathrm{l}$ of cell suspension was transferred into the upper compartment of the cell culture insert and incubated at $37^{\circ} \mathrm{C}$ for $12-48 \mathrm{~h}$. Next, the most superficial cells were wiped with a wet cotton swab and the upper compartment was removed. The polycarbonate membrane was fixed with 4\% paraformaldehyde (CAS 30525-89-4, Santa Cruz Biotechnology) for $15 \mathrm{~min}$ at $25^{\circ} \mathrm{C}$ and then was inverted and stained with $0.1 \%$ crystal violet solution (HT90132, Sigma, USA) for $15 \mathrm{~min}$. Stained cells were counted under a microscope (Zeiss, Axio Imager2, 400x). Six visual fields per chamber were selected for imaging. The number of migrated cells on the lower surface of the polycarbonate membrane was counted within each field. The numbers of cells per group were calculated and were then adjusted to the number in the control group. An uncoated polycarbonate membrane was used to detect the baseline migration ability of colon cancer cells. Finally, the cell invasion/ migration inhibition ratio was calculated with the following formula: ((invading/migrated cells in the control group (n) - invading/ migrating cells in the experimental group (n))/number of invading/migrated cells in the control group) $\times 100 \%$.

\section{Statistical analysis}

All data are presented as the mean \pm standard deviation (SD). Data were analyzed using SPSS $\vee$ 19.0 software (IBM, Armonk, USA). The $\chi^{2}$ test was used to analyze the correlation between CNRIP1 methylation and clinicopathological features. Student's $t$-test was used to analyze the proliferation and invasion/migration of colon cancer cells. Pearson's correlation analysis was used to analyze the correlation between CNRIP1 expression and proliferation of colorectal cancer cells. A $p$-value $<0.05$ was considered statistically significant.

\section{Results}

\section{Levels of CNRIP1 promoter methylation}

Variations in the methylation level at numerous loci within the CNRIP1 promoter region were as sessed in blood drawn from colorectal adenocarcinoma and adenoma patients and healthy volunteers. There were $8 \mathrm{CpG}$ sequences (at positions 2216, 2226, 2231, 2245, 2254, 2273, 2286, and 2325 , denoted with a double-underline in the fol- 
lowing sequence, respectively) within the CNRIP1 promoter region: 5'-GAGCAGCAGTGTCCACCTCACGTAGCTGGCCGAGGCGGTATCCAGATTCCGGGGGTCTCGCTCCTTGGCATAGTGGTCGCTTAACTCCAGCGCCTTCCCAGTGCCTCCCAAACCTCTCCTCCTCCTG CCCGGGGCTGTTCTAGGAGGAGCCTAAATGTC-3'.

The methylation levels in patients with colorectal adenocarcinoma, colorectal adenoma, and healthy volunteers were $85.50 \pm 8.24 \%, 81.33$ $\pm 5.81 \%$, and $63.66 \pm 3.61 \%$, respectively. Sequencing of $\mathrm{CpG}$ islands revealed differences in the methylation levels at loci 2216, 2226, 2231, 2245 , and 2254 within the CNRIP1 promoter region, which was most marked at locus 2245 (Figure 1). Compared with healthy volunteers, the methylation levels in the sample of patients with colorectal adenocarcinoma and colorectal adenoma were significantly higher $(p<0.01$; Table I). There were no significant differences between patients with colorectal adenocarcinoma and colorectal adenoma $(p>0.05$; Table I).

\section{Association between CNRIP1 promoter region methylation status and clinicopathological characteristics of colorectal adenocarcinomas}

The correlations between the methylation status within the CNRIP1 promoter region and clinicopathological characteristics of diagnosed adenocarcinomas were assessed. Based on the methylation levels at locus 2245, patients with adenocarcinoma and adenoma and healthy controls were stratified into methylation $\geq 80 \%$ and methylation $<80 \%$ groups, and $\chi^{2}$ analysis was performed (Table II).

\section{Verification of CNRIP1 overexpression in colon cancer cells}

BLAST comparative analysis of the CNRIP1transfected clone sequence data was conducted with the sequences listed in the database curated by the National Center for Biotechnology Information (NCBI) (Figure 2). The results show that the sequences were consistent with one another, indicating that the CNRIP1 CDS was successfully cloned with the PCDNA3.0 vector.

\section{Levels of CNRIP1 promoter methylation} in colon cancer cell lines

CNRIP1 promoter methylation levels of colon cancer cell lines before and after 5-azaC treatment were analyzed. The average methylation levels within CPG sequences of the CNRIP1 promoter region were $96.9 \%$ (75\% at locus $2216,100 \%$ at $2226,100 \%$ at $2231,100 \%$ at $2245,100 \%$ at $2254,100 \%$ at $2273,100 \%$ at 2286 , and $100 \%$ at $2325)$ before 5 -azaC treatment and $47.5 \%(60 \%$ at locus $2216,60 \%$ at $2226,60 \%$ at $2231,40 \%$ at $2245,40 \%$ at $2254,40 \%$ at $2273,40 \%$ at 2286 , and $40 \%$ at 2325 ) after 5 -azaC treatment (Figure 3 ).

\section{Expression of CNRIP1 mRNA in colon cancer cells}

The results of qPCR show that CNRIP1 mRNA expression was significantly lower $(p<0.05)$ within SW620 colon cancer cells $(0.51 \pm 0.03)$ than in the LoVo colon cancer $(1.00 \pm 0.10)$ and FHC normal colon $(0.79 \pm 0.06)$ cell lines (Figure 4$)$. The CNRIP1 mRNA expression level in SW620 cells after 5-azaC treatment was significantly higher $(2.72 \pm 0.33 ; p<0.05)$ than within untreated SW620 cells ( $1.00 \pm 0.04$; Figure 5$)$. The mRNA expression significantly increased $(p<0.05)$ within cells transfected with a CNRIP1-overexpression plasmid $(68.30 \pm 2.08)$ relative to $S W 620$ cells within the EV group (1.00 \pm 0.04 ; Figure 6).

\section{Expression of CNRIP1 protein in colon cell} lines

The level of CRNIP1 protein expression was determined by Western blot analysis. The CNRIP1 protein expression level within the SW620 colon cancer cell line was significantly lower (0.151 \pm 0.03 ; $p<0.05)$ than within the LoVo colon cancer $(0.287 \pm 0.05)$ and normal FHC colon cell lines $(0.711 \pm 0.04$; Figure 7$)$. Treatment of SW620 cells with 5 -azaC resulted in a significantly increased $(p<0.05)$ level of CNRIP1 protein expression $(0.900 \pm 0.05)$ relative to untreated SW620 cells $(0.329 \pm 0.02$; Figure 8). The level CNRIP1 protein expression was significantly higher $(p<0.05)$ within cells transfected with a CNRIP1-overexpression plasmid $(0.615 \pm 0.05)$ relative to control SW620 cells within the EV group (0.177 \pm 0.03 ; Figure 9$)$.

\section{Proliferation of colon cancer cells}

The proliferative potential was compared between 5-azaC-treated and untreated SW620 colon cancer cells (Figure 10) and between SW620 cells transfected with a CNRIP1-overexpression plasmid and SW620 cells transfected with an empty vector (Figure 11). The proliferative ability of SW620 cells at $96 \mathrm{~h}$ post 5 -azaC treatment was significantly lower $\left(0.792 \pm 0.05 \mathrm{OD}_{450}\right.$; $t=25.812$; $p=0.001)$ than the same cells before 5 -azaC treatment $\left(1.443 \pm 0.02 \mathrm{OD}_{450}\right)$. Moreover, the Pearson correlation showed that proliferative ability of treated SW620 cells positively correlated with the duration of 5 -azaC treatment $(r=0.931 ; p=0.021)$. Meanwhile, the proliferative ability of SW620 cells transfected with CNRIP1-overexpression plasmid at $96 \mathrm{~h}$ was significantly lower $\left(0.95 \pm 0.37 \mathrm{OD}_{450}\right.$; $t=5.382 ; p<0.001)$ than SW620 cells transfected with a control vector $\left(1.29 \pm 0.61 \mathrm{OD}_{450}\right)$. 

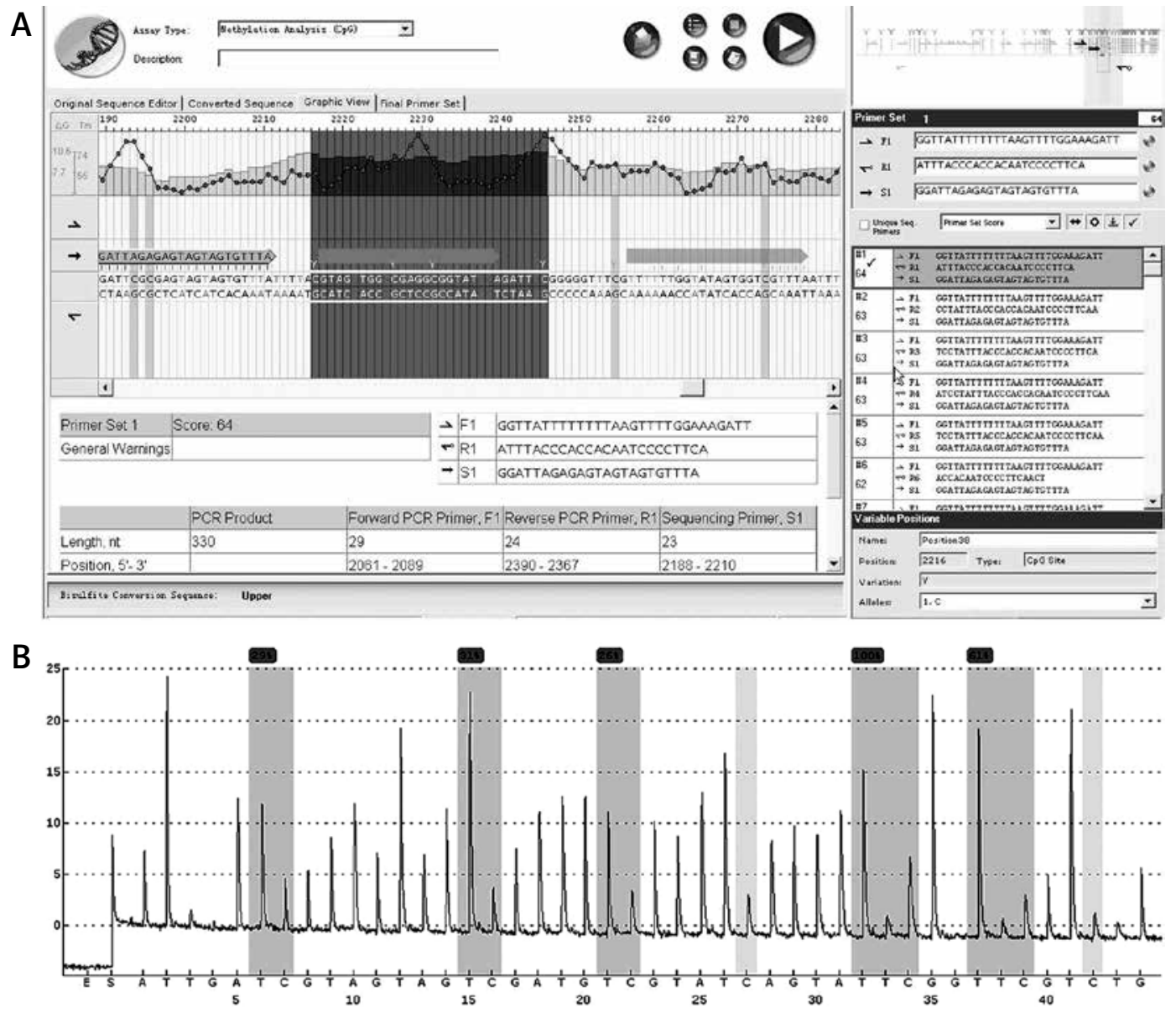

C

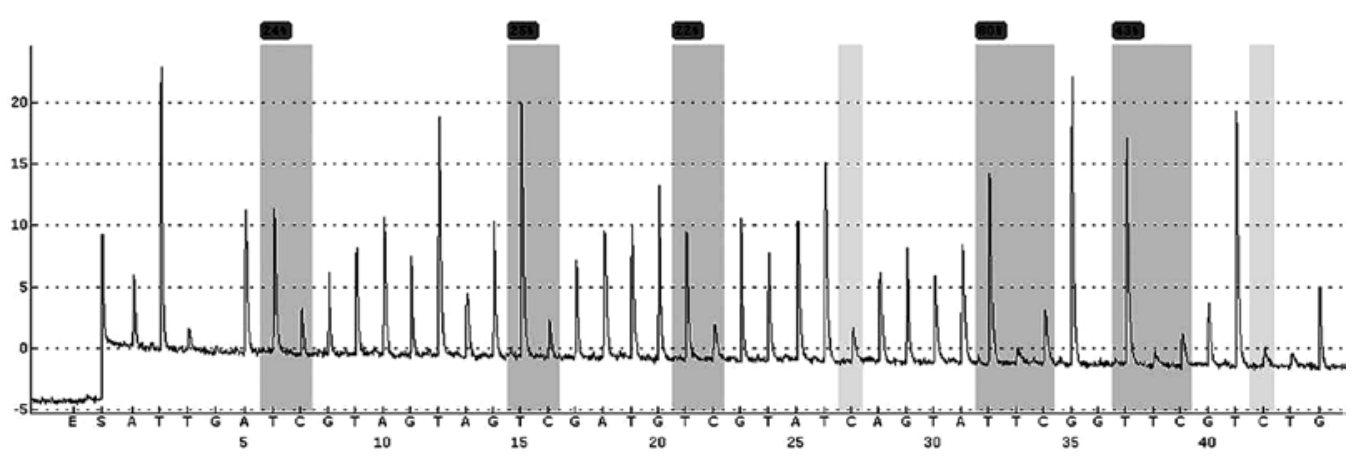

D

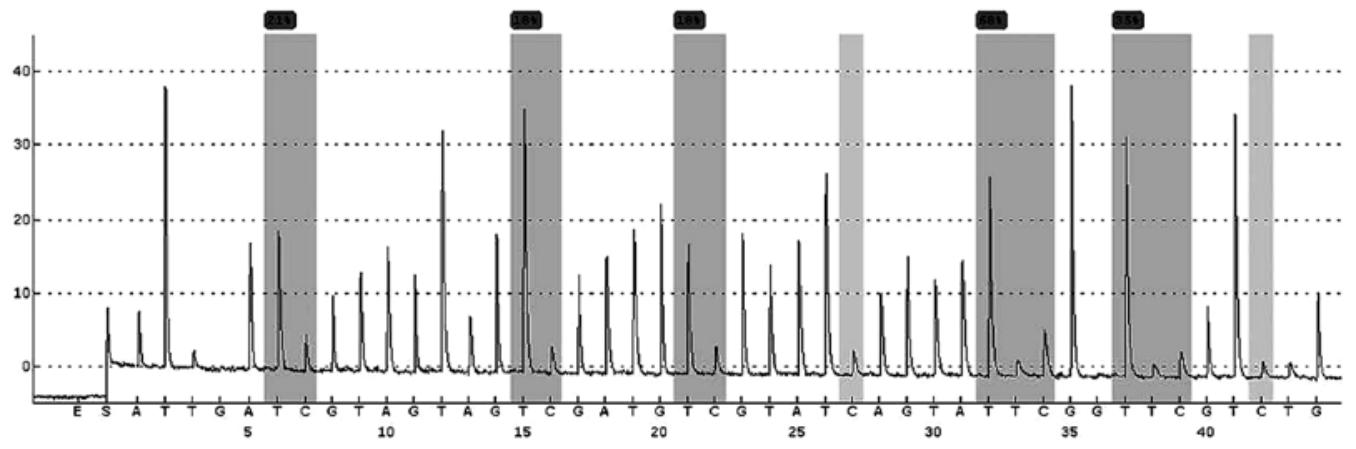

Figure 1. CNRIP1 promoter $\mathrm{CpG}$ island methylation pyrosequencing map of peripheral blood. $\mathbf{A}-$ The pyrosequencing primers were designed using PyroMark Assay Design 2.0, B - colorectal adenocarcinoma patients, C - colorectal adenoma patients, $\mathbf{D}$ - healthy volunteer ( $\mathrm{Y}$ is a degenerate base corresponding to $\mathrm{T}$ and $\mathrm{C}$; methylation level is indicated by percentage). Methylation levels in patients with colorectal adenocarcinoma, colorectal adenoma, and healthy volunteers were $85.50 \pm 8.24 \%, 81.33 \pm 5.81 \%$, and $63.66 \pm 3.61 \%$, respectively. Sequencing of CpG islands revealed differences in the methylation levels at loci 2216, 2226, 2231, 2245, and 2254 within the CNRIP1 promoter region, and it was most marked at locus 2245 
Table I. CNRIP1 promoter methylation levels in peripheral blood sample

\begin{tabular}{|llccc|}
\hline Variable & $\boldsymbol{N}$ & CNRIP1 promoter methylation levels (\%) & $\boldsymbol{t}$ value & $\boldsymbol{P}$-value \\
\hline CRC patients & 50 & $85.50 \pm 8.24$ & 5.94 & $0.008^{*}$ \\
\hline Colorectal adenoma patients & 20 & $81.33 \pm 5.81$ & 6.50 & $0.000^{\#}$ \\
\hline Healthy volunteers & 20 & $63.66 \pm 3.61$ & 2.10 & $0.089^{\star}$ \\
\hline
\end{tabular}

${ }^{*} p<0.05$ (CRC patients compared with healthy volunteers); ${ }^{*} p<0.05$ (colorectal adenoma patients compared with healthy volunteers); $\Delta p>0.05$ (CRC patients compared with colorectal adenoma patients).

Table II. Correlation between CNRIP1 promoter methylation and clinicopathological characteristics of colorectal adenocarcinoma

\begin{tabular}{|c|c|c|c|c|c|}
\hline \multirow{2}{*}{$\begin{array}{l}\text { Clinicopathological } \\
\text { parameters }\end{array}$} & \multirow[t]{2}{*}{$N=50$} & \multicolumn{2}{|c|}{ CNRIP1 methylation } & \multirow[t]{2}{*}{$\chi^{2}$ value } & \multirow[t]{2}{*}{$P$-value } \\
\hline & & $\geq 80 \%$ & $<80 \%$ & & \\
\hline \multicolumn{6}{|l|}{ Gender: } \\
\hline Male & 28 & 19 & 9 & 0.001 & 0.981 \\
\hline Female & 22 & 15 & 7 & & \\
\hline \multicolumn{6}{|l|}{ Age [years]: } \\
\hline$\geq 60$ & 31 & 24 & 7 & 3.326 & 0.068 \\
\hline$<60$ & 19 & 10 & 9 & & \\
\hline \multicolumn{6}{|l|}{ Tumor location: } \\
\hline Ascending colon & 19 & 14 & 5 & 1.283 & 0.864 \\
\hline Transverse colon & 3 & 2 & 1 & & \\
\hline Descending colon & 4 & 3 & 1 & & \\
\hline Sigmoid colon & 6 & 3 & 3 & & \\
\hline Rectum & 18 & 12 & 6 & & \\
\hline \multicolumn{6}{|l|}{ General classification: } \\
\hline Mass type & 8 & 5 & 3 & 0.139 & 0.933 \\
\hline Infiltrating type & 19 & 13 & 6 & & \\
\hline Ulcerative type & 23 & 16 & 7 & & \\
\hline \multicolumn{6}{|l|}{ Tumor diameter $[\mathrm{cm}]$ : } \\
\hline$\leq 3$ & 21 & 8 & 13 & 14.880 & $<0.001^{*}$ \\
\hline$>3$ & 29 & 26 & 3 & & \\
\hline \multicolumn{6}{|l|}{ Differentiation: } \\
\hline High & 9 & 3 & 6 & 6.941 & $0.031^{*}$ \\
\hline Medium & 23 & 16 & 7 & & \\
\hline Low & 18 & 15 & 3 & & \\
\hline \multicolumn{6}{|l|}{ Depth of invasion: } \\
\hline Tis & 23 & 10 & 13 & 11.847 & $0.003^{*}$ \\
\hline $\mathrm{T} 1+\mathrm{T} 2$ & 15 & 13 & 2 & & \\
\hline $\mathrm{T} 3+\mathrm{T} 4$ & 12 & 11 & 1 & & \\
\hline \multicolumn{6}{|c|}{ Lymph node metastasis: } \\
\hline NO & 33 & 19 & 14 & 4.847 & $0.028^{*}$ \\
\hline $\mathrm{N} 1+\mathrm{N} 2$ & 17 & 15 & 2 & & \\
\hline \multicolumn{6}{|l|}{ Distant metastasis: } \\
\hline MO & 44 & 29 & 15 & 0.737 & 0.391 \\
\hline M1 & 6 & 5 & 1 & & \\
\hline \multicolumn{6}{|l|}{ TNM staging: } \\
\hline$I+I I$ & 27 & 13 & 14 & 10.630 & $0.001^{*}$ \\
\hline III + IV & 23 & 21 & 2 & & \\
\hline
\end{tabular}

${ }^{*} p<0.05$. 


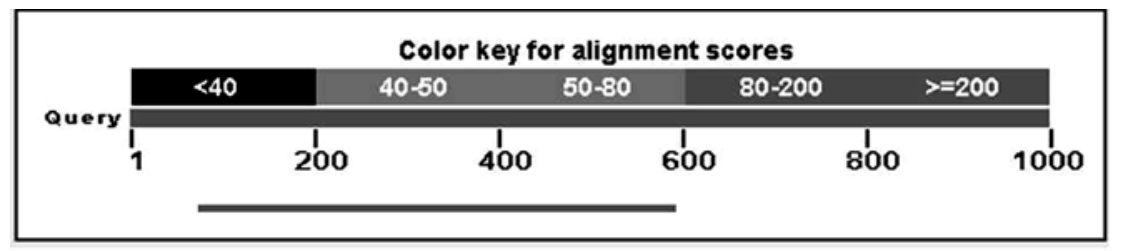

Sequences producing significant alignments

Select: All None Selected:0

\begin{tabular}{|c|c|c|c|c|c|c|}
\hline \multicolumn{7}{|l|}{ 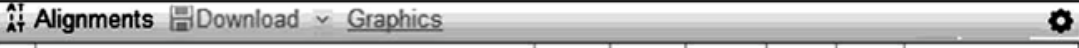 } \\
\hline Description & $\begin{array}{l}\text { Max } \\
\text { score }\end{array}$ & $\begin{array}{l}\text { Total } \\
\text { score }\end{array}$ & $\begin{array}{l}\text { Query } \\
\text { cover }\end{array}$ & $\begin{array}{c}E \\
\text { value }\end{array}$ & Ident & Accession \\
\hline$\square$ None provided & 944 & 944 & $52 \%$ & 0.0 & $99 \%$ & Query_245001 \\
\hline
\end{tabular}

\begin{tabular}{|c|c|c|c|c|c|c|}
\hline \multirow{2}{*}{\multicolumn{5}{|c|}{$\begin{array}{l}\text { Sequence ID: Ic||Query_245001 Length: } 522 \text { Number of Matches: } 1 \\
\text { Range 1: } 1 \text { to } 520 \text { Graphics }\end{array}$}} & \multirow{2}{*}{\multicolumn{2}{|c|}{$\nabla$ Next Match $\mathbf{\Delta}$ Previous $\mathrm{M}$}} \\
\hline & & & & & & \\
\hline \multicolumn{2}{|c|}{$\begin{array}{l}\text { Score } \\
944 \text { bits(511) } \\
\end{array}$} & $\begin{array}{l}\text { Expect } \\
0.0\end{array}$ & $\begin{array}{l}\text { Identities } \\
517 / 520(99 \%)\end{array}$ & $\begin{array}{l}\text { Gaps } \\
0 / 520(0 \%)\end{array}$ & $\begin{array}{l}\text { Strand } \\
\text { Plus/Minus }\end{array}$ & \\
\hline \multirow[t]{2}{*}{ Query } & \multirow[t]{2}{*}{76} & \multirow{2}{*}{\multicolumn{4}{|c|}{$\begin{array}{l}\text { TAGCATCAGAAaGAGCCACTTTCAGAGGAaGgaCtCCTTGTTCACCCACATCAGACTGCG } \\
|||||||||||||||||||||||||||||||||||||||||||||||||||||||||| \mid\end{array}$}} & \multirow[t]{2}{*}{135} \\
\hline & & & & & & \\
\hline Sbjet & 520 & TAGCATCAGAAAGA & CACTTTCAGAGGAAG & GACTCCTTGTTC & CACCCACATCAGACTGCG & 461 \\
\hline \multirow[t]{2}{*}{ Query } & 136 & \multirow{2}{*}{\multicolumn{4}{|c|}{ 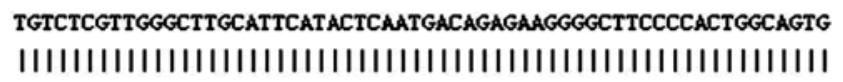 }} & 195 \\
\hline & & & & & & \\
\hline Sbjet & 460 & \multicolumn{4}{|c|}{ TGTCTCGTTGGGCTTGCATTCATACTCAATGACAGAGAAGGGGCTTCCCCACTGGCAGTG } & 401 \\
\hline \multirow[t]{2}{*}{ Query } & 196 & \multirow{2}{*}{\multicolumn{4}{|c|}{$\begin{array}{l}\text { AGCCCGCTTGTGGTAATTGTAGAACTTGACTTGCCACACTGTCTCGAAGGTCCCAATGTC } \\
|||||||||||||||||||||||||||||||||||||||||||||||||||||||| \mid\end{array}$}} & 255 \\
\hline & & & & & & \\
\hline Sbjet & 400 & \multicolumn{4}{|c|}{ ATCCCGCTTGTGGTAATTGTAGAACTTGACTTGCCACACTGTCTCGAAGGTCCCAATGTC } & 341 \\
\hline \multirow[t]{2}{*}{ Query } & 256 & \multicolumn{4}{|c|}{ TGTGAACGGCATGGTGATCTGGATGGGTTGCCGTTCTCCACTCTTCGTTGGGGTCACACC } & 315 \\
\hline & & \multicolumn{4}{|c|}{ IIIIIIIIIIIIIIIIIIIIIIIIIIIIIIIIIIIIIIIIIIIIIIIIIIIIIIII } & \\
\hline Sbjet & 340 & \multicolumn{4}{|c|}{ TGTGAACGGCATGGTGATCTGGATGGGTTGCCGTTCTCCACTCTTCGTTGGGGTCACACC } & 281 \\
\hline \multirow[t]{2}{*}{ Query } & 316 & \multicolumn{4}{|c|}{ TTCTGTGTCATATGTACCCGTATAAACAACTCTGTCCCCATCAGGCTCTTTAGACTTCAG } & 375 \\
\hline & & \multicolumn{4}{|c|}{ IIIIIIIIIIIIIIIIIIIIIIIIIIIIIIIIIIIIIIIIIIIIIIIIII } & \\
\hline Sbjet & 280 & \multicolumn{4}{|c|}{ TTCTGTGTCATATGTACCCGTATAAACAACTCTGTCCCCATCAGGCTCTTTAGACTTCAG } & 221 \\
\hline \multirow[t]{2}{*}{ Query } & 376 & \multicolumn{4}{|c|}{ TTCCAGTGGGACAAGCACACCACCAATGGAAATATTCTCGACCTGCAGCGTGCTGGGCTT } & 435 \\
\hline & & \multicolumn{4}{|c|}{ IIIIIIIIIIIIIIIIIIIIIIIIIIIIIIIIIIIIIIIIIIIIIIIIIIIIIIII II } & \\
\hline Sbjet & 220 & \multicolumn{4}{|c|}{ TTCCAGTGGGACAAGCACACCACCAATGGAAATATTCTCGACCTGCAGCGTGCTGGGTTT } & 161 \\
\hline \multirow[t]{2}{*}{ Query } & 436 & \multicolumn{4}{|c|}{ AATCTTCACCTCAACCTTGTAGGAGGAGCCGGTGGGCAGCTTGATGGTGCGGTTCTGGCC } & 495 \\
\hline & & \multicolumn{4}{|c|}{ IIIIIIIIIIIIIIIIIIIIIIIIIIIII IIIIIIIIIIIIIIIIIIIIII } & \\
\hline Sbjet & 160 & \multicolumn{4}{|c|}{ AATCTTCACCTCAACCTTGTAGGAGGAGCCGGTGAGCAGCTTGATGGTGCGGTTCTGGCC } & 101 \\
\hline Query & 496 & GAAGCGCTGCCCGT & CCTTGTAAAAGACC & GGGCCGTCATTA & AGGCTGGATGCGCAGCGC & 555 \\
\hline & & \|\|\|\|\|\|\|\|$\|$ & \|\|\|\|\|\|\|\| & \|\|\|\|\|\|$\|$ & \|\|\|\|\|\|\|\|\|\|\|\| & \\
\hline Sbjet & 100 & GAAGCGCTGCCCGT & ACCTTGTAAAAGACC & GGGCCGTCATTA & AGGCTGGATGCGCAGCGC & 41 \\
\hline Query & 556 & GATGGAGAGGCGCA & GGCCCGGCAGGTCC & CCCATGTCT 5 & 595 - Results of seque & encing \\
\hline & & \|\|\|\|\|\|$\|$ & \|\|\|\|\|\|$\|$ & $\|I\|\|\|$ & & \\
\hline Sbjet & 40 & GATGGAGAGGCGCA & AGGCCCGGCAGGTCC & CCCATGTCT 1 & $\begin{array}{l}\text { - The known seq } \\
\text { in the NCBI dat }\end{array}$ & puences \\
\hline
\end{tabular}

Figure 2. Verification of CNRIP1 overexpression in colon cancer cells. BLAST comparative analysis of the CNRIP1-transfected clone sequence data was conducted with the sequences listed in the database curated by the National Center for Biotechnology Information (NCBI). Sequences were consistent with one another, thereby indicating that the CNRIP1 CDS was successfully cloned via our PCDNA3.0 vector 


\section{Invasion and migration of colon cancer cells}

We then compared the invasive and migration ability of 5-azaC treated and untreated SW620 colon cancer cells and SW620 cells transfected with a CNRIP1-overexpression plasmid and SW620 cells transfected with an empty vector. Treatment of SW620 cells with 5 -azaC for 96 h significantly decreased their invasive $(57.33 \pm 15.92$ cells/ well) and migration ability (79.83 \pm 9.50 cells/ well), when compared to the invasiveness (150.00 \pm 11.80 cells/well; $t=8.50, p=0.001$; Figure 12) and migration (154.33 \pm 17.48 cells/well; $t=8.18$, $p=0.001$; Figure 13) of untreated SW620 cells.

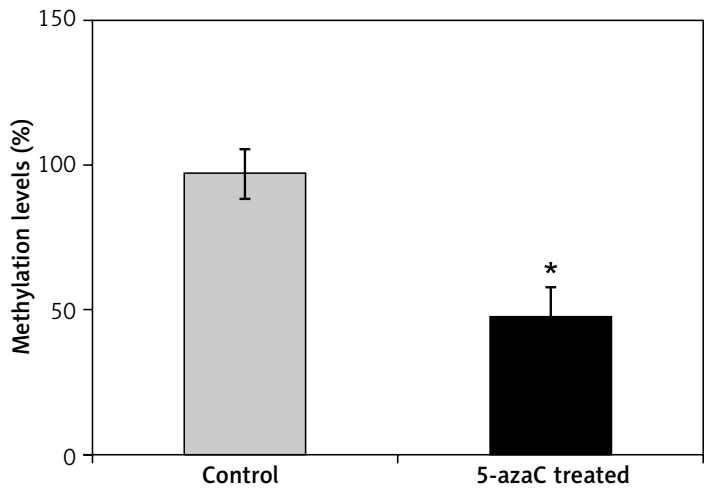

Figure 3. CNRIP1 promoter methylation level in colon cancer cell lines. CNRIP1 promoter methylation levels of colon cancer cell lines before and after 5-azaC treatment were analyzed. The average methylation levels within CpG sequences of the CNRIP1 promoter region were $96.9 \%(75 \%$ at locus $2216,100 \%$ at $2226,100 \%$ at $2231,100 \%$ at 2245 , $100 \%$ at $2254,100 \%$ at $2273,100 \%$ at 2286 , and $100 \%$ at 2325 ) before 5 -azaC treatment and $47.5 \%$ (60\% at locus $2216,60 \%$ at $2226,60 \%$ at 2231 , $40 \%$ at $2245,40 \%$ at $2254,40 \%$ at $2273,40 \%$ at 2286 , and $40 \%$ at 2325 ) after 5 -azaC treatment

${ }^{*} p<0.05$ (control vs. 5-azaC treated).

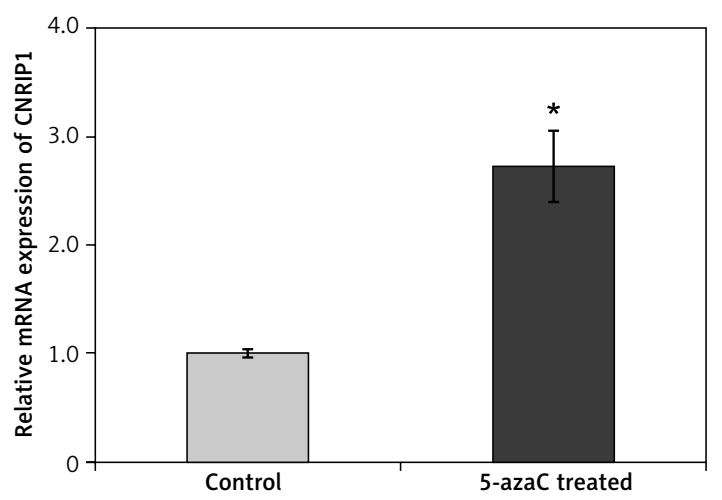

Figure 5. CNRIP1 mRNA expression levels in colon cancer cells before and after 5 -azaC treatment. The CNRIP1 mRNA expression level in SW620 cells after 5 -azaC treatment was significantly higher $(2.72$ \pm 0.33 ; $p<0.05)$ than within SW620 cells not treated with 5 -azaC $(1.00 \pm 0.04)$

${ }^{*} p<0.05$ (control vs. 5-azaC treated).
Furthermore, transfection of SW620 cells with a CNRIP1-overexpression plasmid significantly reduced their invasiveness (94.00 \pm 16.24 cells/ well) and migration ability (101.5 \pm 13.89 cells/ well), when compared to the invasiveness (171.83 \pm 13.93 cells/well; $t=9.642, p=0.000$; Figure 14 ) and migration ability (134.33 \pm 5.72 cells/well; $t=5.126, p=0.004$; Figure 15) of SW620 colon cancer cells transfected with an empty vector.

\section{Discussion}

The present study found that the methylation status at locus 2245 within the CpG island re-

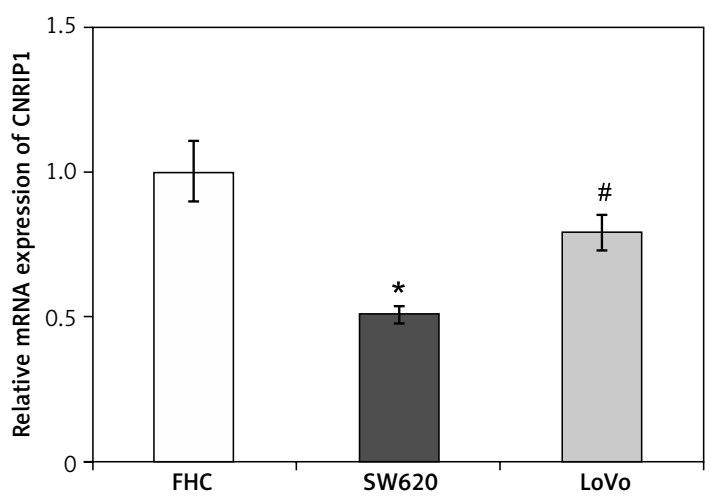

Figure 4. CNRIP1 mRNA expression in colon cells. CNRIP1 mRNA expression was significantly lower $(p<0.05)$ within the SW620 colon cancer cell line $(0.51 \pm 0.03)$ than in the LoVo colon cancer $(1.00$ $\pm 0.10)$ and $\mathrm{FHC}$ normal colon $(0.79 \pm 0.06)$ cell lines ${ }^{*} p<0.05$ (SW620 vs. FHC), ${ }^{*} p<0.05$ (SW620 vs. LoVo).

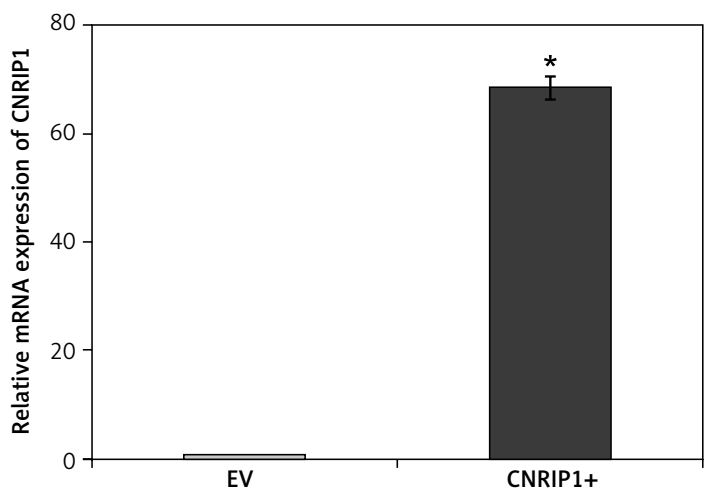

Figure 6. CNRIP1 mRNA expression levels in colon cancer cells before and after transfection with a CNRIP1-overexpression plasmid. The mRNA expression significantly increased $(p<0.05)$ within cells transfected with a CNRIP1-overexpression plasmid $(68.30 \pm 2.08)$ relative to SW620 cells within the EV group $(1.00 \pm 0.04)$

${ }^{*} p<0.05$ (CNRIP1 vs. EV). 

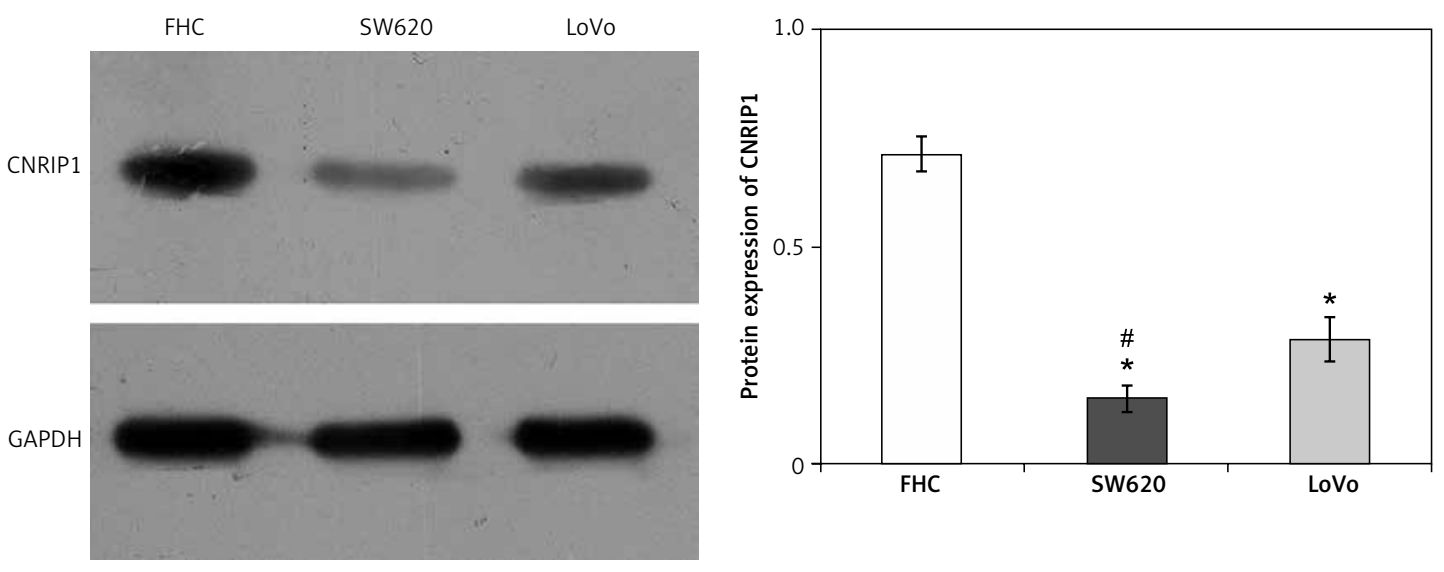

Figure 7. CNRIP1 protein expression levels within colon cell lines. The CNRIP1 protein expression level within the SW620 colon cancer cell line was significantly lower $(0.151 \pm 0.03 ; p<0.05)$ than within the LoVo colon cancer $(0.287 \pm 0.05)$ and normal FHC colon cell lines $(0.711 \pm 0.04)$. CRNIP1 protein expression was determined by Western blotting

${ }^{*} p<0.05$ (SW620 vs. FHC), \#p $<0.05$ (SW620 vs. LoVo).
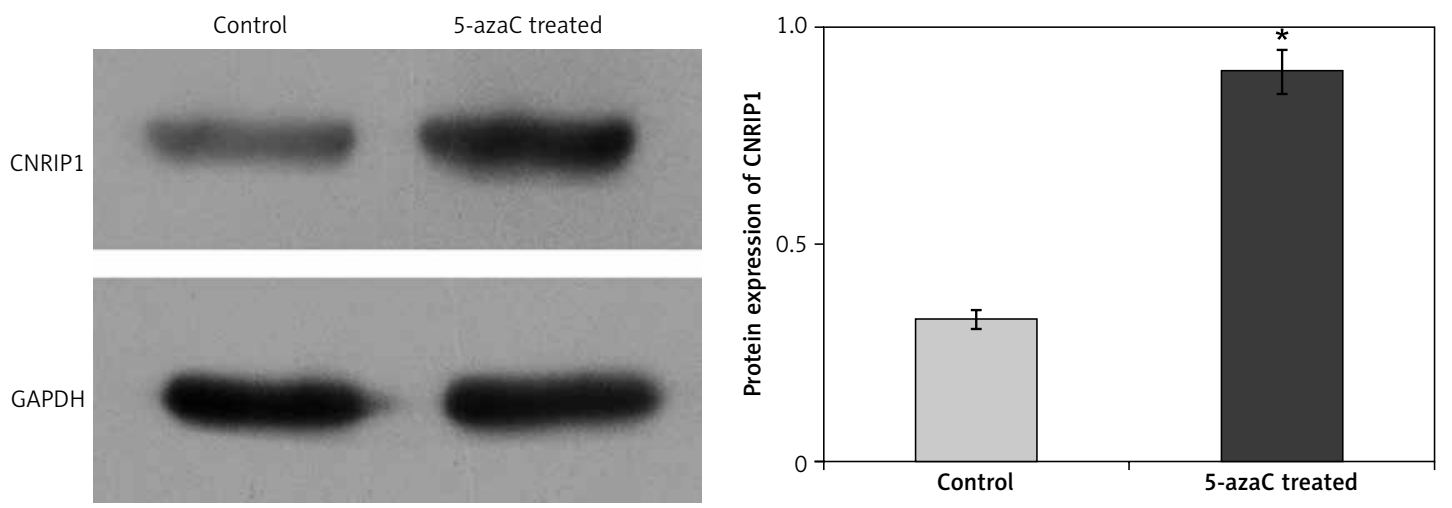

Figure 8. CNRIP1 protein expression levels within colon cancer cell lines treated with 5-azaC. Treatment of SW620 with 5 -azaC resulted in a significantly increased $(p<0.05)$ level of CNRIP1 protein expression $(0.900 \pm 0.05)$ relative to untreated SW620 cells $(0.329 \pm 0.02)$

${ }^{*} p<0.05$ (5-azaC treated vs. control).

EV

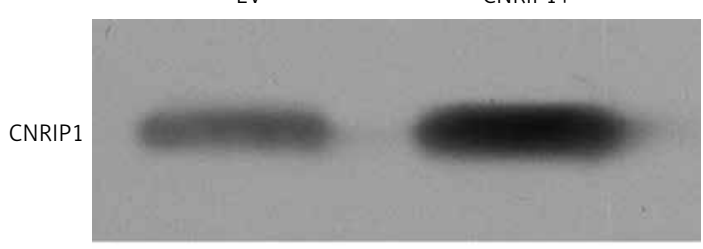

GAPDH

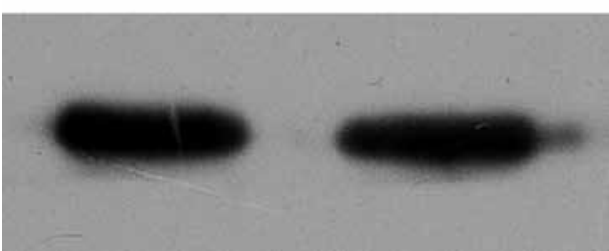

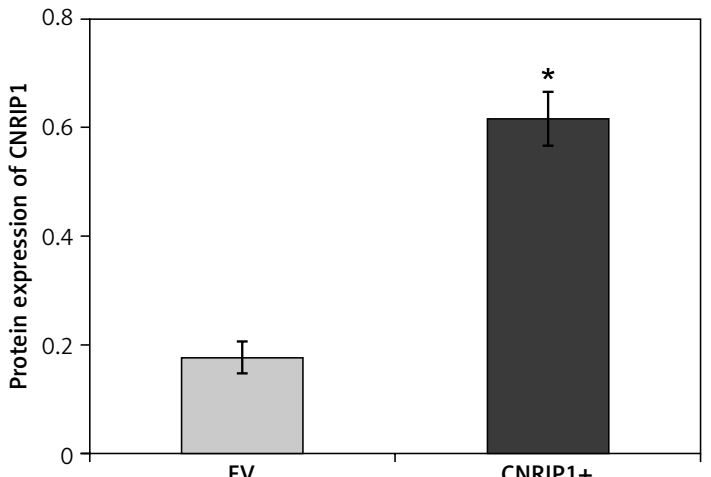

CNRIP1+

Figure 9. CNRIP1 protein expression levels within colon cancer cell lines treated with a CNRIP1-overexpression plasmid. The level of CNRIP1 protein expression was significantly higher $(p<0.05)$ within cells transfected with a CNRIP1-overexpression plasmid $(0.615 \pm 0.05)$ relative to control SW620 cells within the EV group $(0.177 \pm 0.03)$ ${ }^{*} p<0.05$ (CNRIP1+ vs. EV). 


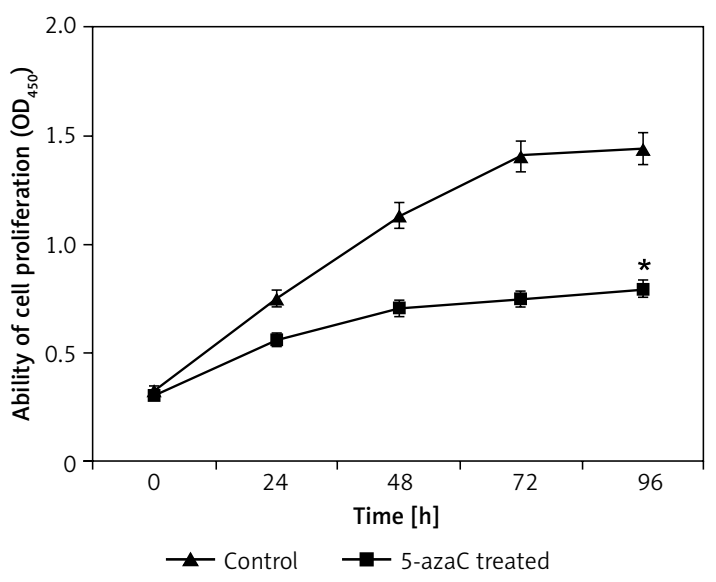

Figure 10. Proliferation of colon cancer cells treated with 5 -azaC. The proliferative ability of SW620 cells at $96 \mathrm{~h}$ after 5 -azaC treatment was significantly lower $\left(0.792 \pm 0.05 \mathrm{OD}_{450} ; t=25.812 ; p=\right.$ 0.001 ) than the same cells before 5 -azaC treatment $\left(1.443 \pm 0.02 \mathrm{OD}_{450}\right)$

${ }^{*} p<0.05$ (5-azaC treated vs. control).
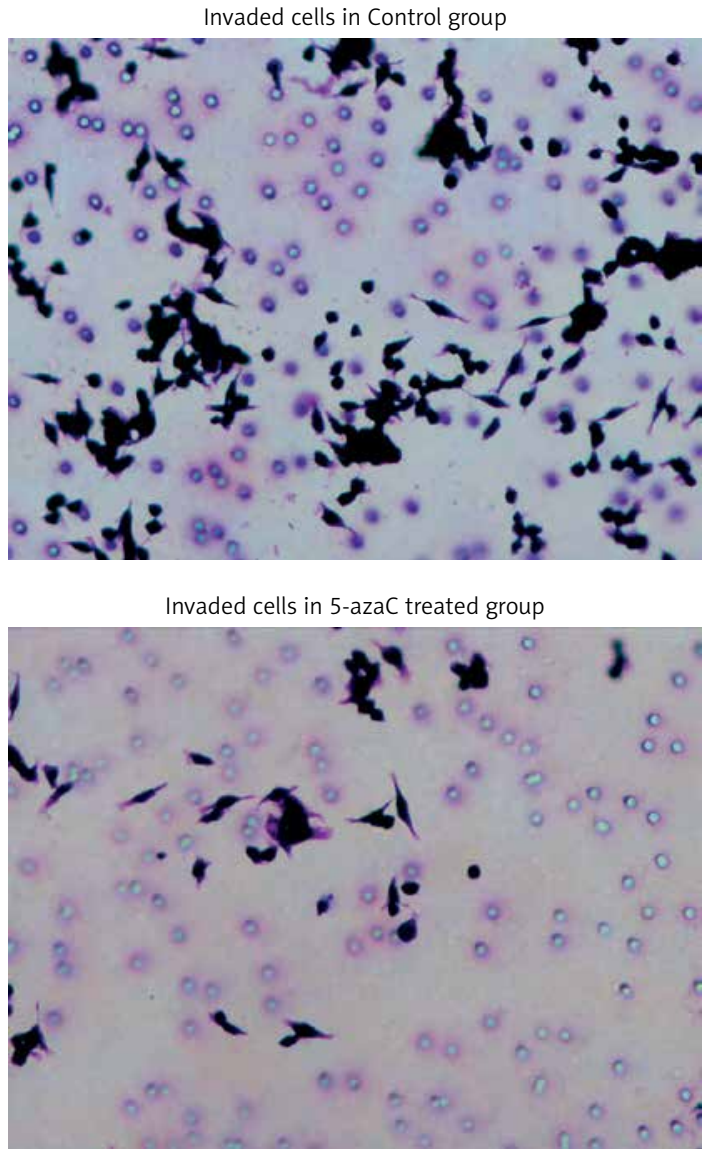

gion of the CNRIP1 promoter region was greater from the peripheral blood of patients with colorectal adenocarcinoma than within healthy controls. Furthermore, the methylation level at the 2245 locus significantly correlated with tumor diameter, the depth of primary tumor invasion,

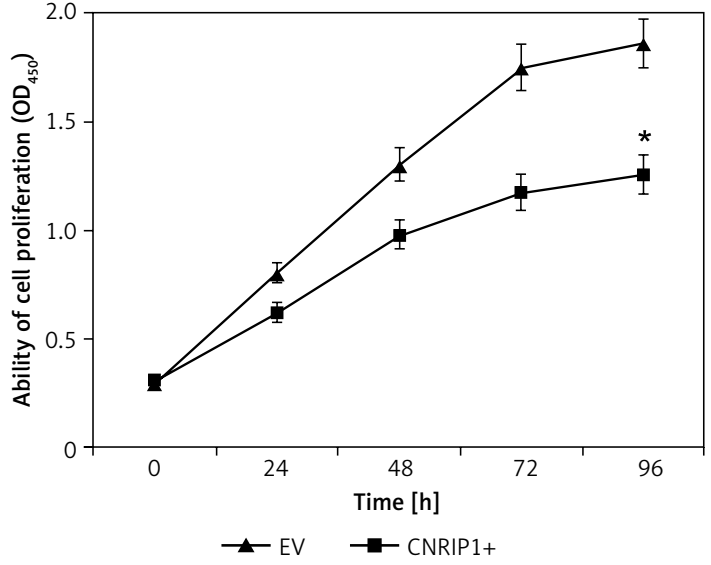

Figure 11. Proliferation of cancer cells transfected with a CNRIP1-overexpression plasmid. The proliferative ability of SW620 cells transfected with a CNRIP1-overexpression plasmid was significantly lower $\left(0.95 \pm 0.37 \mathrm{OD}_{450} ; t=5.382 ; p<0.001\right)$ than SW620 cells transfected with a control vector (1.29 $\left.\pm 0.61 \mathrm{OD}_{450}\right)$

${ }^{*} p<0.05$ (CNRIP1+ vS. EV).

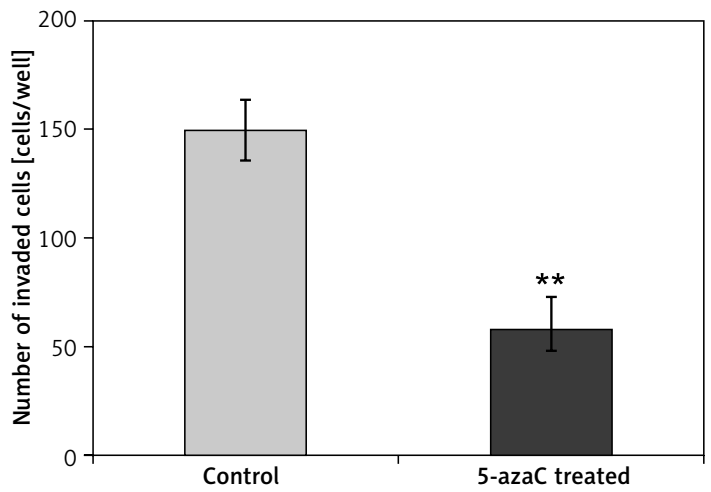

Figure 12. Invasion of colon cancer cells treated with 5-azaC. Treatment of SW620 cells with 5-azaC for $96 \mathrm{~h}$ significantly decreased their invasiveness (57.33 \pm 15.92 cells/well) when compared to the invasiveness of untreated SW620 cells $(150.00$ \pm 11.80 cells/well; $t=8.50 ; p=0.001$ )

${ }^{* *} p<0.01$ (5-azac treated vs. Control).

TNM stage, tumor grade, and lymph node metastasis, therefore suggesting that the degree of methylation level may have prognostic value. The results also show that the methylation status of locus 2245 was higher within colorectal adenoma patients, thereby highlighting its potential 

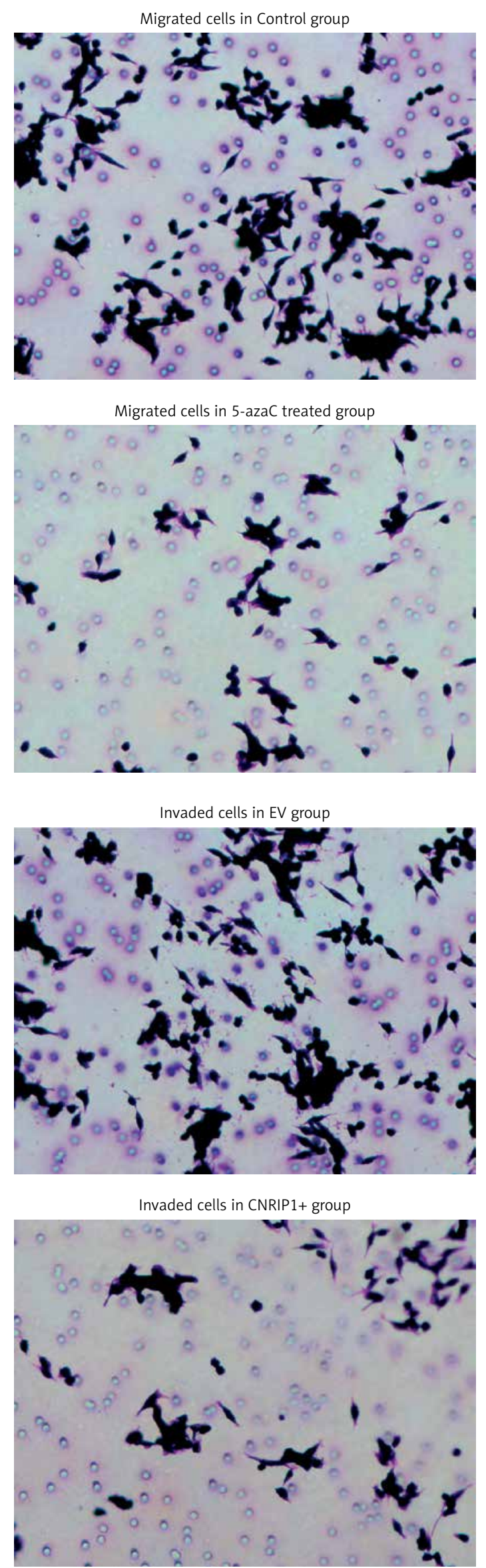

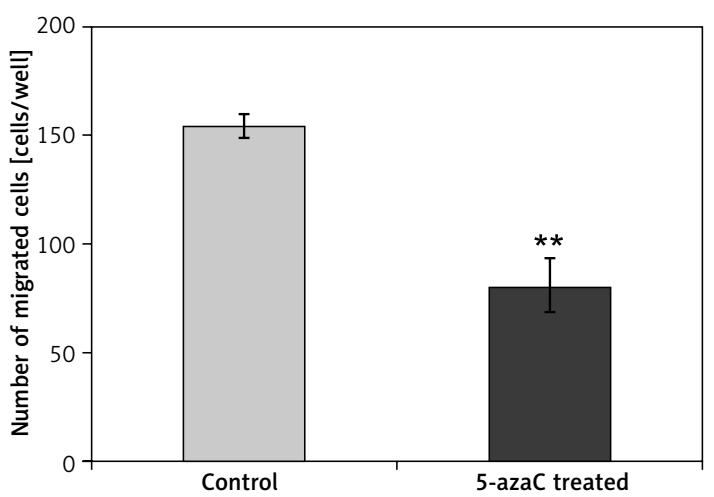

Figure 13. Migration of colon cancer cells treated with 5-azaC. Treatment of SW620 cells with 5-azaC for $96 \mathrm{~h}$ significantly decreased their migration ability $(79.83 \pm 9.50$ cells/well) when compared to the migration of untreated SW620 cells (154.33 \pm 17.48 cells/well; $t=8.18 ; p=0.001)$

${ }^{* *} p<0.01$ (5-azaC treated vs. Control).

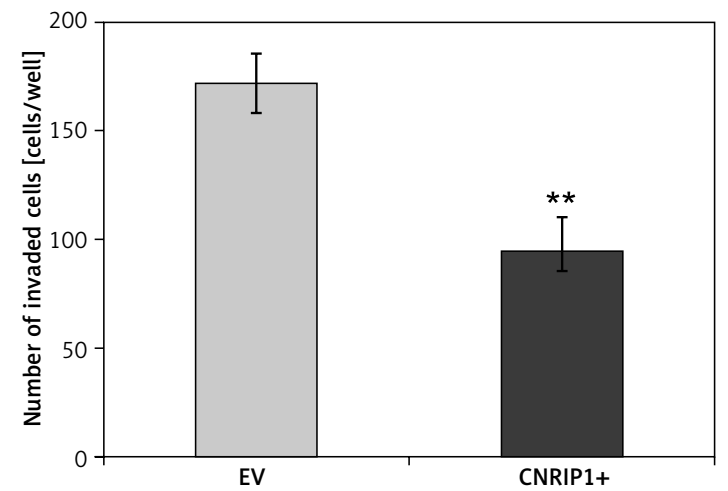

Figure 14. Invasion of colon cancer cells transfected with a CNRIP1-overexpression plasmid. Transfection of SW620 cells with a CNRIP1-overexpression plasmid significantly reduced their invasiveness (94.00 \pm 16.24 cells/well) when compared to the invasiveness of SW620 colon cancer cells transfected with an empty vector $(171.83 \pm 13.93$ cells/well; $t=9.642 ; p<0.001)$

${ }^{* *} p<0.01$ (CNRIP1+ vs. EV). 

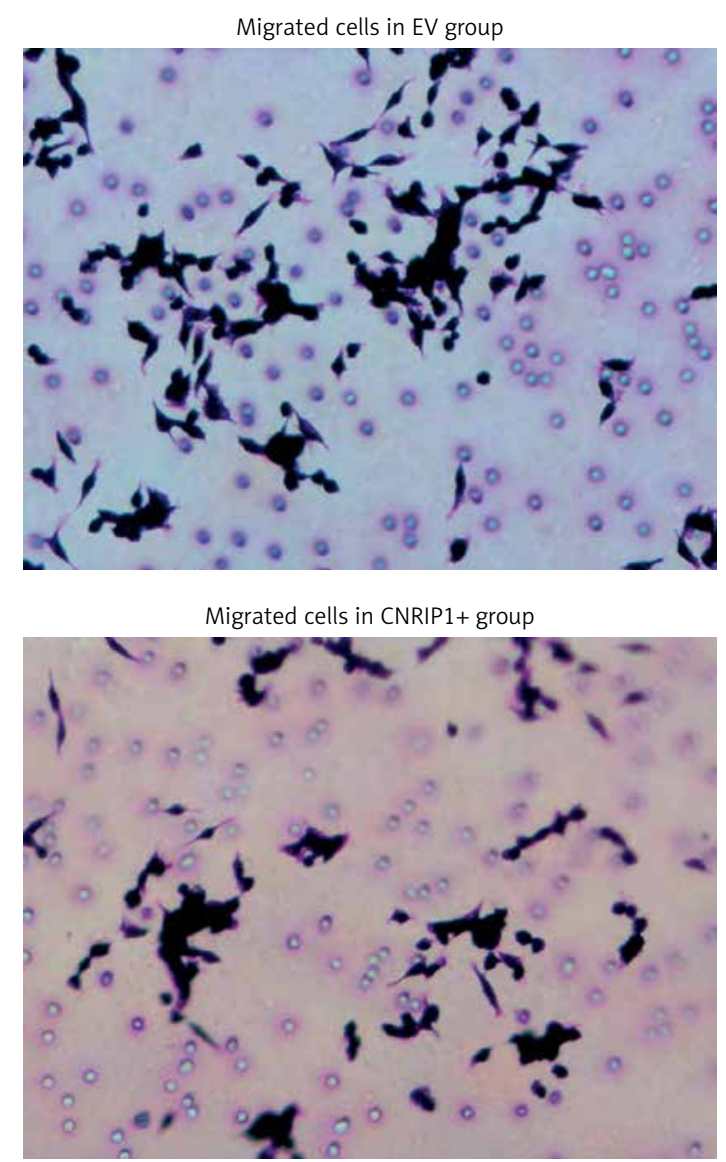

as a screening tool. Accordingly, screening the peripheral blood drawn from the general population for the methylation status at locus 2245 in the CPG island region of the CNRIP1 promoter may be helpful for detecting the precancerous colorectal adenoma, which can be excised before developing into cancer, or non-advanced adenocarcinomas, which are highly treatable and have more favorable outcomes.

To date, there have been few studies investigating the role of CNRIP1 and its methylation in dysplastic and normal human body tissues. In order to verify the effect of CNRIP1 methylation on the proliferative, invasive and migration ability of colorectal cancer cells, we used qPCR and Western blotting to select a low CNRIP1 expression SW620 colon cancer cell line for cell function assays. We first used 5 -azaC to suppress methylation in treated SW620 cells. We found that, after 5-azaC treatment, CNRIP1 mRNA expression and protein synthesis in SW620 cells were significantly increased, whereas the methylation level of the CNRIP1 promoter in SW620 cells was significantly reduced $(p<0.05)$. CCK-8 and Transwell assays were then used to detect the proliferative, invasive and migration abilities of colon cancer cells, wherein we found that the proliferative, invasion and migration abilities of SW620 cells were sig-

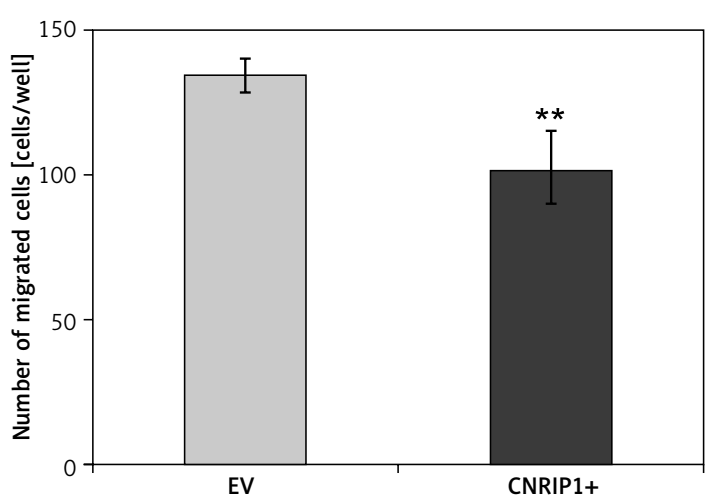

Figure 15. Migration of colon cancer cells transfected with a CNRIP1-overexpression plasmid. Transfection of SW620 cells with a CNRIP1-overexpression plasmid significantly reduced their migration ability (101.5 \pm 13.89 cells/well) when compared to the migration ability of SW620 colon cancer cells transfected with an empty vector (134.33 \pm 5.72 cells/well; $t=5.126, p=0.004)$

${ }^{* *} p<0.01($ CNRIP1+ vs. EV).

nificantly decreased $(p<0.05)$ after the treatment of 5-azaC-induced methylation suppression, and that the performance of cells in such assays correlated with the duration of 5 -azaC treatment. Our study results suggest that hypomethylation of the CNRIP1 promoter region significantly decreases the proliferative, invasive and migration abilities of SW620 colon cancer cells. Could CNRIP1 promoter demethylation be a potential therapeutic for treating colorectal cancer?

In order to verify the effect of CNRIP1 overexpression on the activity of colorectal cancer cells, the CNRIP1-overexpression lentiviral plasmid was constructed and transfected into SW620 colon cancer cells. We found that, compared with the colon cancer cells transfected with an empty vector, the cell proliferative, invasive and migration ability of colon cancer cells overexpressing CNRIP1 were significantly reduced $(p<0.05)$. Our results suggest that CNRIP1 could be a tumor suppressor gene and that inducing CNRIP1 overexpression could be developed into a valuable colorectal cancer therapeutic.

\section{Acknowledgments}

This study was supported by grants from the Natural Science Foundation of Zhejiang Province, 
China (No. LQ16C080001), Medical Scientific Research Project of Zhejiang Province, China (No. 2015KYB372) and the Public Welfare Technical Applied Research Project of Huzhou City (Key Program) (No. 2015GZ14).

\section{Conflict of interest}

The authors declare no conflict of interest.

\section{References}

1. Siegel RL, Miller KD, Jemal A. Cancer statistics, 2015. CA Cancer J Clin 2015; 65: 5-29.

2. Siegel R, Ward E, Brawley O, Jemal A. Cancer statistics, 2011: the impact of eliminating socioeconomic and racial disparities on premature cancer deaths. CA Cancer J Clin 2011; 61: 212-36.

3. Leslie A, Carey FA, Pratt NR, Steele RJ. The colorectal adenoma-carcinoma sequence. Br J Surg 2002; 89: 845-60.

4. Center MM, Jemal A, Smith RA, Ward E. Worldwide variations in colorectal cancer. CA Cancer J Clin 2009; 59: 366-78.

5. Davis CD, Uthus EO. DNA methylation, cancer susceptibility, and nutrient interactions. Exp Biol Med (Maywood) 2004; 229: 988-95.

6. Yiu AJ, Yiu CY. Biomarkers in colorectal cancer. Anticancer Res 2016; 36: 1093-102.

7. Ladabaum U, Allen J, Wandell M, Ramsey S. Colorectal cancer screening with blood-based biomarkers: cost-effectiveness of methylated septin 9 DNA versus current strategies. Cancer Epidemiol Biomarkers Prev 2013; 22: 1567-76.

8. Wu HC, Shen J, Yang HI, Tsai WY, Chen CJ, Santella RM. Blood DNA methylation markers in prospectively identified hepatocellular carcinoma cases and controls from Taiwan. World J Hepatol 2016; 8: 301-6.

9. Warton K, Mahon KL, Samimi G. Methylated circulating tumor DNA in blood: power in cancer prognosis and response. Endocr Relat Cancer 2016; 23: R157-71.

10. Vatandoost N, Ghanbari J, Mojaver M, et al. Early detection of colorectal cancer: from conventional methods to novel biomarkers. J Cancer Res Clin Oncol 2016; 142: 341-51.

11. Naumov VA, Generozov EV, Zaharjevskaya NB, et al. Genome-scale analysis of DNA methylation in colorectal cancer using Infinium HumanMethylation450 BeadChips. Epigenetics 2013; 8: 921-34.

12. Carmona FJ, Azuara D, Berenguer-Llergo A, et al. DNA methylation biomarkers for noninvasive diagnosis of colorectal cancer. Cancer Prev Res (Phila) 2013; 6: 656-65.

13. Nan H, Giovannucci EL, Wu K, et al. Pre-diagnostic leukocyte genomic DNA methylation and the risk of colorectal cancer in women. PLoS One 2013; 8: e59455.

14. Tokarz P, Blasiak J. Role of DNA methylation in colorectal cancer. Postepy Biochem 2013; 59: 267-79.

15. Bethge N, Lothe RA, Honne $\mathrm{H}$, et al. Colorectal cancer DNA methylation marker panel validated with high performance in Non-Hodgkin lymphoma. Epigenetics 2014; 9: 428-36.

16. Zheng X, Suzuki T, Takahashi C, Nishida E, Kusakabe M. cnrip1 is a regulator of eye and neural development in Xenopus laevis. Genes Cells 2015; 20: 324-39.

17. Andresen K, Boberg KM, Vedeld HM, et al. Four DNA methylation biomarkers in biliary brush samples accurately identify the presence of cholangiocarcinoma. Hepatology 2015; 61: 1651-9.
18. Chong Y, Mia-Jan K, Ryu H, et al. DNA methylation status of a distinctively different subset of genes is associated with each histologic Lauren classification subtype in early gastric carcinogenesis. Oncol Rep 2014; 31: 2535-44.

19. Tewari S, Bhatia V, Goel MM, et al. Performance charac teristics of bisulfite conversion and SYBR green based quantitative PCR for DNA methylation analysis. J Environ Biol 2013; 34: 667-71.

20. Edge SB, Compton CC. The American Joint Committee on Cancer: the 7th edition of the AJCC cancer staging manual and the future of TNM. Ann Surg Oncol 2010, 17: 1471-4.

21. Livak KJ, Schmittgen TD. Analysis of relative gene expression data using real-time quantitative PCR and the 2(-Delta Delta C(T)) method. Methods 2001; 25: 402-8. 